\title{
Osteogenesis Imperfecta: potential therapeutic approaches
}

\author{
Maxime Rousseau Corresp., 1 , Jean-Marc Retrouvey ${ }^{2}$ \\ 1 Faculty of Dentistry, McGill University, Montreal, Canada \\ 2 Faculty of Dentistry, Department of Orthodontics, McGill University, Montreal, Canada \\ Corresponding Author: Maxime Rousseau \\ Email address: maxime.rousseau2@mail.mcgill.ca
}

Osteogenesis imperfecta is a genetic disorder that is usually caused by disturbed production of collagen type I. Depending on its severity in the patient, this disorder may create difficulties and challenges for the dental practitioner. The goal of this article is to provide guidelines based on scientific evidence found in the current literature for practitioners who are or will be involved in the care of these patients. A prudent approach is recommended, as individuals affected by OI present with specific dentoalveolar problems that may prove very difficult to address.

Recommended treatments for damaged/decayed teeth in the primary dentition are full-coverage restorations, including stainless steel crowns or zirconia crowns. Full-coverage restorations are also recommended in the permanent dentition. Intracoronal restorations should be avoided, as they promote structural tooth loss. Simple extractions can also be performed, but not immediately before or after intravenous bisphosphonate infusions. Clear aligners are a promising option for orthodontic treatment. In severe OI types, such as III or IV, orthognathic surgery is discouraged, despite the significant skeletal dysplasia present. Given the great variations in the severity of OI and the limited quantity of information available, the best treatment option relies heavily on the practitioner's preliminary examination and judgment. A multidisciplinary team approach is encouraged and favoured in more severe cases, in order to optimize diagnosis and treatment. 


\section{Osteogenesis Imperfecta: potential therapeutic approaches}

2 Maxime Rousseau ${ }^{1}$, Jean-Marc Retrouvey ${ }^{2}$

$3{ }^{1}$ Faculty of Dentistry, McGill University, Montreal, QC, Canada

$4 \quad{ }^{2}$ Faculty of Dentistry, Director Craniofacial, McGill University, Montreal, QC, Canada

5

6

7

8

9

10

11

12 Corresponding Author:

13 Maxime Rousseau ${ }^{1}$

142001 McGill College Avenue, Suite 100, Montreal, QC, H3A 1G1, Canada

15 Email address: maxime.rousseau2@mail.mcgill.ca

16

17

18

19

20

21

22

23 


\section{Abstract}

25 Osteogenesis imperfecta is a genetic disorder that is usually caused by disturbed production of

26 collagen type I. Depending on its severity, this disorder may create difficulties and challenges

27 for the dental practitioner. The goal of this article is to provide guidelines based on scientific

28 evidence found in the current literature for practitioners who are or will be involved in the care

29 of these subjects. A prudent approach is recommended, as individuals affected by OI present

30 with specific dentoalveolar problems that may prove very difficult to address.

31 Recommended treatments for damaged ordecayed teeth in the primary dentition are full-

32 coverage restorations, including stainless steel crowns or zirconia crowns. Full-coverage

33 restorations are also recommended in the permanent dentition. Intracoronal restorations should

34 be avoided, as they promote structural tooth loss. Simple extractions may also be performed

35 after multidisciplinary concertation, but not immediately before or after intravenous

36 bisphosphonate infusions. Clear aligners are a promising option for orthodontic treatment. In

37 severe OI types, such as III or IV, orthognathic surgery is discouraged, despite the significant

38 skeletal dysplasia present. Given the great variations in the severity of OI and the limited

39 quantity of information available, the best treatment option relies heavily on the practitioner's

40 preliminary examination and judgment. A multidisciplinary team approach is encouraged and

41 favoured in more severe cases, in order to optimize diagnosis and treatment. 


\section{Introduction}

45 Osteogenesis imperfecta (OI), or "brittle bone disease," is caused by mutations in the collagen

46 type I genes COL1A1 and COL1A2 (or other collagen genes for rarer types of OI), causing

47 production of a defective collagen type I that results in significant alterations in different tissues

48 in the body. However, the defective collagen affects bones more than it does most other organs

49 (Forlino \& Marini 2016). Typical signs of OI are small stature, fragile bones, scoliosis, blue

50 sclera and Shields type I dentinogenesis imperfecta (DI). Four main types of OI have been

51 described by Sillence (Sillence et al. 1979), and this classification is still the most commonly

52 used today, though more clinically defined types were later described by Rauch and Glorieux

53 (Rauch \& Glorieux 2004) (Table 1).

It is important to note that these OI types are not named in terms of severity. Rather, the

55 severity of OI increases as follows: type I, type IV, type III, and type II. OI types V, VI, and VII

56 are quite rare, and their disease severity tends to be similar to OI type IV. It is important to

57 realize that disease severity is a continuum, and that classification into types is not an exact

58 science. Even within a particular type of OI, there is great variability in disease characteristics.

59 Thus, the degree of severity of manifestations such as DI, scoliosis, and bone fragility can be

60 very different from one subject to another, even if both subjectpresent the same OI type.

\section{Survey Method}

63 Literature searches were performed with "dental" and "osteogenesis imperfecta," as in dental manifestations of OI. The queries were performed through the Biosis (78 articles), Embase (362

65 articles), Medline (245 articles), and Web of Science (189 articles) databases. Altogether, the 
66 search yielded 874 articles. Relevant articles were screened by examination of the titles and

67 abstracts. Case studies, case reports, or animal studies were included in the final selection. Eighty

68 articles were retained for the literature review and read in their entirety.

\section{Medical Management}

71 There is currently no cure for OI, as the underlying genetic cause cannot be directly addressed.

72 However, symptomatic treatment options are available and are used according to clinical disease severity. Subjects with mild OI type I may not need any medical treatment if they are fully mobile and experience few fractures. However, many of the more severely affected subjects receive intravenous bisphosphonates to increase bone mineral density and to reduce fracture rates (Glorieux 2008). In growing children, this treatment also helps to reshape vertebrae which were compressed by fractures. Bisphosphonate therapy seems to be less effective in adults than in children (Shapiro et al. 2010). require surgical interventions to straighten out long bones with metal rods that are placed into the bone marrow cavity (Ruck et al. 2011). Subjects with scoliosis may need spinal fusion surgery.

82 Physiotherapy programs and regular physical exercise are other key components of subject management (Rauch et al. 2002) (Cheung \& Glorieux 2008). 


\section{Dental Manifestations and Treatments}

85

86

87

Dentinogenesis Imperfecta and its Management

OI subjects present more dental problems than the average population (Sæves et al. 2009). The main dental manifestation of OI is dentinogenesis imperfecta (DI) (Barron et al. 2008; Levin et al. 1983; Vital et al. 2012), but it is not visibly present in every subject affected by OI. The prevalence of DI varies by Type, from $21 \%$ to $73 \%$, as reported in the literature (Majorana et al. 2010). DI is present in $25 \%$ of the OI type I population (Paterson et al. 1983), $60 \%$ of OI type IV, and up to $80 \%$ of OI type III. OI type V and VI do not seem to be affected by DI (Schwartz \& Tsipouras 1984a). The DI present in OI subjects is classified as Shields dentinogenesis imperfecta type I (Shields 1983) and is characterized by yellow to bluish-brown discoloration of teeth due to abnormal dentine (Jindal et al. 2009; Shields et al. 1973) and short roots. Initially, the primary pulp chambers are uncharacteristically large, but they will calcify fairly rapidly. The enamel, although normal, is prone to fracture due to the deficient dentinoenamel junction, which is smooth instead of scalloped (Delgado et al. 2008).

Studies suggest that teeth affected by DI are not at greater risk of developing carious lesions (Shapira 2001). This slow progression of caries is thought to be caused by the random nature of the dentinal tubules and the fact that there are fewer tubules (Teixeira et al. 2008). The primary dentition is usually more vulnerable to breakdown by DI than the permanent, although permanent teeth are still prone to deterioration over time (Waltimo et al. 1996a). Although DI is not always clinically detectable in all OI subjects, some characteristics may still be observed due to the large degree of variation in the severity of the disease (Levin et al. 1983; Waltimo et al. 1996a; Waltimo et al. 1996b). Precautions regarding restorative dentistry should be taken in all OI subjects, as their teeth may still be affected despite a negative clinical diagnosis of DI (Lund 
107 et al. 1997). Obliteration of the pulp chambers, short roots, and bulbous crowns may compromise

108 the restorability of the dentition.

109 For subjects affected with moderate to severe OI, and especially if combined with DI, a 110 multidisciplinary team approach is the current recommendation, to ensure that the diagnosis is

111 accurate and that treatment approaches are optimized (Cheung et al. 2011). The dental team

112 should include a pediatric dentist, a periodontist, an oral surgeon, an orthodontist, and a

113 restorative dentist. The diagnostic procedure involves a thorough clinical examination,

114 panoramic and periapical radiographs, and a complete family history.

Before contemplating restorative interventions, a thorough radiological and clinical

116

117

118

119

120

121

122

123

124

125

126 127 include:

128

examination of the dentition must be performed to assess the degree of pulpal calcification, the

shape of the teeth, and the length of the root. It is also important to consider the clinical

restorability of each tooth with a prognosis for long-term success, as well as to maintain adequate vertical dimension of occlusion until natural exfoliation occurs. Also, it is important to consider the subject's need for serial magnetic resonance imaging due to the medical condition.

Restorative options that are favorable for this type of imaging may be indicated (Shapira 2001).

Histologic analysis of the primary dentition upon exfoliation is indicated, if possible, when the subject is treated in a hospital environment. This procedure will allow for an assessment of the severity of the DI and help the practitioner better evaluate the subject's condition (Wright \& Gantt 1985).

Benefits of early treatment in the primary dentition of children with DI (Herold 1972)

- Maintaining dental health while preserving tooth structure 
- Providing ideal aesthetic appearance

- Preserving function of dentition and maintaining the vertical dimension of occlusion (VDO)

- Avoiding premature loss of primary teeth while maintaining the stability of arch length

- Establishing a dental home which allows for building a relationship with a dental team and reinforces the importance of oral health

At present, the consensus is that, if needed, treatment should be initiated at an early stage, as the subject's dentition tends to deteriorate with an associated breakdown of tooth structure over time (O'Connell \& Marini 1999). Typically, treatment should be completed before or at the time of the full primary dentition eruption. Most often, general anesthesia is necessary due to the inability to use other advanced behavior guidance techniques in children with OI. Special care is needed during anesthesia and dental treatment due to the subject's need for immobilization and risk of fracture. Depending on the severity of DI presentation, a one or two-stage approach can be used. Ideal treatment would consist of a one-stage approach and treating all primary teeth once they have erupted and are in occlusion. However, if the condition needs treatment prior to all teeth being erupted, a two-stage approach can be used (Herold 1972). A stainless steel crown or a full ceramic crown should be placed if the tooth shows signs of weakness and if it starts to fracture. The best option will usually be the one that puts the least amount of stress on the tooth and supporting bone (Malmgren \& Lindskog 2003; Teixeira et al. 2008). Full coverage restorations are the treatment of choice, since intracoronal restorations are very poorly retained in DI teeth and may actually promote fractures (Majorana et al. 2010). Clinically, all primary teeth show signs of breakdown from DI, with primary canines being least affected. Generally, the permanent dentition is less affected (O’Connell \& Marini 1999). Dental sealants placed on newly 
152 erupted permanent molars may offer supplemental protection and are strongly recommended 153 (Delgado et al. 2008; Leal et al. 2010; O'Connell \& Marini 1999). In young adults that have a

154 permanent dentition affected by moderate to severe DI, full coronal coverage is preferred when

155 clinical or radiological signs of post-eruptive breakdowns are diagnosed (Siadat et al. 2007). This 156 treatment method may enhance survival/retention.

157 Severely fractured or non-restorable teeth are better off extracted, as tooth prognosis 158 becomes guarded/poor, thus limiting the restorative treatment options. In some cases, if the 159 subject is asymptomatic, or if the medical condition does not allow dental treatment and no 160 clinical or radiographic signs of infection exist, it can be indicated to monitor the dental 161 condition. Teeth deemed non-restorable or those not candidates for pulpal therapy should be 162 extracted, with consideration given to space maintenance. Teeth that are candidates for pulpal 163 therapy might fulfill the requirements for full-coverage restorations and frequent radiographic 164 follow-up. Endodontic treatment carried out on teeth of subjects affected by DI may prove 165 difficult given the altered morphology and calcification.

166 OI subjects not diagnosed with DI may still present with abnormal dental development 167 that may weaken their structure. Short root and slender shape, abnormal pulpal calcification, or 168 other morphological anomalies are significant clues that the dentition is not normally developed 169 (Leal et al. 2010) (Figure 1). The treatment plan for such individuals should depend on 170 comprehensive clinical observations by the dentist and should be correlated with the severity of 171 the OI type. 
174 One of the issues encountered when dealing with young subjects affected by OI is delayed and

175 ectopic eruptions (Malmgren \& Norgren 2002b). These manifestations may be accentuated by

176 bisphosphonate treatments, as the physiologic mechanism of bone resorption around the dental

177 sac is disturbed either by the OI condition or by the use of bisphosphonates (Kamoun-Goldrat et

178 al. 2008; Malmgren et al. 2016). Missing and impacted teeth are also common findings,

179 especially in type III OI associated with DI (Malmgren et al. 2016) (Figure 2).

The best approach in these cases will depend strongly on the severity of the subject's

181

182

183

184

\section{Malocclusions Management in OI}

194 Subjects affected by OI will show craniofacial manifestations of the disease to varying extents, 195

condition and the position of the impacted tooth or teeth and missing teeth. OI type I subjects presenting with impactions may be treated with conventional orthodontics, while more severe types of OI which present complex impactions may require surgical assistance (Chang et al. 2007a). It is safe to try to limit surgery, as their success rate and healing process may be affected by the OI severity and bisphosphonate treatment (Schwartz \& Tsipouras 1984a).

OI type I cases present with the least challenges, while OI type III affected by DI tends to create much more difficult clinical situations (Rizkallah et al. 2013). Impacted teeth, especially upper canines, may be brought into the arch during orthodontic treatment when performed on OI type I subjects. It may be advisable to postpone the removal or surgical exposure of asymptomatic, impacted teeth in severe OI subjects, to avoid potential surgical complications and further loss of alveolar bone (Malmgren \& Norgren 2002a). depending on the severity of their condition (Rizkallah et al. 2013; Vital et al. 2012). Triangular- 
196 like face shape and low ears are the most widely reported facial bone features found in OI

197 subjects, especially in types III and IV (Rauch \& Glorieux 2004). This phenomenon was

198 investigated on an animal model and partially explained in a study conducted by Eimar and his

199 team (Eimar et al. 2016). The characteristics were attributed to the disproportionate relationship

200 between the subject's small chins and large malar bones. These subjects very often show signs of

201 restrained vertical dimension, flattened cranial base, relative prognathism, and more forward,

202 counterclockwise mandibular growth (Chang et al. 2007b). Studies (Chang et al. 2007b;

203 Rizkallah et al. 2013) have shown that OI subjects tend to be prone to more severe and unique

204 malocclusions than unaffected subjects. It was shown that Class III malocclusions occur more

205 readily in subjects affected by OI (Schwartz \& Tsipouras 1984b; Waltimo-Siren et al. 2005)

206 (Figure 3). Lateral open bites, a rare finding in the general population, as well as anterior

207 crossbites, have a much higher incidence in the OI population than in unaffected subjects

208 (Rizkallah et al. 2013). However, few reports of successful orthodontic treatments are present in

209 the literature (Hartsfield et al. 2006). OI type I subjects who present moderate malocclusions and

210 no severe DI may be treated cautiously, especially if orthognathic surgery is contemplated

211 (Tashima et al. 2011). Not enough clinical data is available about outcomes of orthodontic

212 treatments in moderate to severe OI subjects to issue clear treatment guidelines. Intervention at

213 an early age may be best, since the subject's dentition and malocclusion tend to worsen over

214 time. It is also believed that the best option is usually the one that puts the least amount of stress

215 on teeth and bone, as they are more fragile (Malmgren \& Lindskog 2003; Teixeira et al. 2008).

216 One approach used in non-OI subjects presenting with anterior and posterior crossbites consists

217 of rapid maxillary expansion and a protraction face mask (Kapust et al. 1998; Kim et al. 1999).

218 This procedure has been time-tested and is efficient in the unaffected population (Mandall et al. 
219 2016). However, this procedure may be cause for concern in OI subjects, as the development of

220 the bone mass in the maxilla is defective in all OI subjects, particularly type III and IV. The

221 application of orthopedic forces to fragile bones and teeth with compromised sutural growth

222 potential may be detrimental to the treatment outcome. The transverse discrepancy found in

223 severe OI subjects may be too large to benefit from rapid maxillary expansion significantly, and

224 root morphology may not respond well to the large forces applied. In conclusion, maxillary

225 expansion in OI subjects must be approached with caution, especially in moderate to severe OI.

226 It is probably contraindicated in severe OI-DI subjects. The vertical dimension, in the case of

227 lateral open bites, should be prioritized to restore occlusal contacts in the posterior segments,

228 even if the dentition is to remain in crossbite after treatment. The anteroposterior correction may

229 be attempted with light intermaxillary elastics, which put much less stress on the dentition and

230 bony structures than a protraction device. Orthognathic surgery, if it involves a maxillary

231 repositioning, is not routinely recommended due to high morbidity, potential excessive bleeding,

232 and relapse (Hartsfield et al. 2006; Lewis \& Stoker 1987). The goal of orthodontic treatment in

233 these subjects is not to correct minor aesthetic imperfections, but to restore a functional

234 occlusion. It is also important to select subjects carefully. Appliances that put heavy stress on

235 bones and teeth, such as a face mask, are strongly discouraged. Clear aligners, as tested by the

236 author, may prove to be the best alternative in applicable cases (Figure 4).

238 Osteonecrosis of the Jaw (ONJ) - Potential Risks

239 There were initial concerns regarding bisphosphonate treatments, especially intravenous (IV)

240 infusions administered to subjects affected by OI, related to the possibility of subjects developing

241 osteonecrosis of the jaw following dental procedures or even simple extractions (Kos et al. 2010; 
242 Ruggiero et al. 2004). Bisphosphonates decrease osteoclasts' activity, which in turn affect the

243 mechanism of bone repair, maintenance, and remodeling. High dosage of bisphosphonates can

244 also reduce blood supply to a wound, creating a potential risk for ONJ (Schwartz et al. 2008).

245 Four studies looked into the risks of osteonecrosis of the jaw in subjects affected with OI.

246 One of these studies followed five subjects who had at least one tooth extraction, and none

247 showed evidence of ONJ four or sixty months after extraction (Johnson \& Hodgson 2010).

248 Another study followed fifteen subjects who had extractions, mostly of primary teeth, during or

249 after completion of the bisphosphonate treatment. No complications were reported after the

250 extractions, and the healing times were within the expected norm (Schwartz et al. 2008). The

251 third study is a systematic review that looked at five publications. This review covered a total of

252163 subjects who were subjected to dental surgery (surgical and nonsurgical dental extractions

253 and/or manipulations of bone) while undergoing bisphosphonates treatment. No osteonecrosis of

254 the jaw was reported (Chahine et al. 2008; Hennedige et al. 2013; Maines et al. 2012). Even if

255 ONJ has not been linked to bisphosphonate-treated OI subjects, it is recommended that

256 extractions not be performed immediately prior to or immediately after bisphosphonate

257 administration. Delaying infusion of intravenous bisphosphonate has been found to cause

258 increased bone pain for some subjects. If treatment is stopped for long enough, there may be a

259 higher risk of having a fracture (Rauch et al. 2007). As the half-life of bisphosphonates is very

260 long (Fleisch 1997), waiting for more than a week before dental procedures will not significantly

261 affect the outcome or lower the morbidity of the procedure. We recommend twenty-four to forty-

262 eight hours to ensure that the bisphosphonates are absorbed and out of the bloodstream. It is

263 important to note that withdrawing the medication is not thought to make any difference in the 
264 surgical outcome. Bisphosphonates have a ten-year half-life and will accumulate in the bone for

265 up to three half-lives, or thirty years (Fleisch 1991).

266 ONJ usually occurs when high dosages of IV bisphosphonates are administered. However,

267 information is still limited regarding OI subjects, and we have yet to discover the risks regarding

268 dental implants in long-term BP treatment (Schwartz et al. 2008).

\section{Dental Implants}

270 Dental implants are a popular modality to replace missing teeth, and they have become very

271 reliably used in the general population. OI type I may receive dental implants if their overall

272 periodontal condition is not compromised and bone density at the site is adequate to

273 accommodate the implant. Cone beam CT radiography in addition to a thorough clinical

274 examination may assist the clinician in assessing the amount and quality of bone present in the

275 edentulous area before planning the insertion of dental implants in this area. More severe cases

276 such as type III and IV OI subjects present more risks, as bone density and healing potential may

277 be compromised. A few cases have been reported in the literature showing success in integration

278 of implants. A publication described a subject suffering from OI type IV with complete upper

279 and lower dentures supported by six maxillary posterior and five mandibular anterior

280 osseointegrated implants (Prabhu et al. 2007). There was also a report of successful implant

281 therapy in a subject affected by type III OI where 4 implant supported metal ceramic crowns

282 were placed as a treatment for mandibular anterior teeth agenesis (Wannfors et al. 2009).

283 Cone beam computerized tomographic (CBCT) studies should be considered as part of

284 the preliminary investigations for implant therapy. The main advantages of this type of imaging 
285 is that it enables practitioners to visualize skeletal asymmetry in 3D space as well as teeth and

286 root orientation (Figure 5).

287

288

289

290

291

292

293

Moreover, cone beam CT have the ability to allow for accurate measurement and quantification of the craniofacial anomalies present in OI subjects. Even if OI subjects present with specific craniofacial anomalies such as a retrognathic and hypoplastic maxilla, a prognathic mandible and asymmetric cranial features, preliminary studies have failed to directly craniofacial malformations with OI types. More studies at the genetic levels and involving potential correlation between observed and measured craniofacial deformities and the genetic "mapping" of OI subjects should be performed.

To our knowledge, no prospective or retrospective study of a large enough sample has been published. Our recommendation would be to approach implant dentistry with caution in cases of moderate to severe OI, as the failure rate may be higher than in the unaffected population due to the inherently poor bone architecture and remodeling capacities (Hartsfield et al. 2006). The risk of failure and complications may be increased with prolonged use of IV bisphosphonates.

\section{Conclusion}

Given a great deal of variability in the degree of severity of OI subjects, treatment plans may vary. It is the practitioner's responsibility to ensure that the treatment is tailored to the subject's condition. OI Type I may be treated in general practice with a particular attention to the DI condition and bisphosphonate intake. Most severe types, such as non-ambulatory type IIIs, may be better served in dedicated treatment centres, due to compromised dentition, severe 
307

308

309

310

311

312

313

314

315

316

317

318

319

320

321

322

323

324

325

326

327

328

329

330

331

332

333

334

335

336

337

338

339

malocclusions, and general health issues. New pharmacological therapies currently being investigated include teriparatide in adult subjects (Orwoll et al. 2014) and denosumab in growing subjects (Hoyer-Kuhn et al. 2014). Both have seen positive results in recent clinical trials.

Mesenchymal stem cell therapy for OI is also under development and preliminary experiments on mouse models show promising results (Prockop 2017).

\section{Acknowledgements}

This literature review would not have been possible without the cooperation of the subject's seen under the BBDC 7701 protocol and the help of the McGill Faculty of Dentistry librarian, Mr.

Martin Morris.

\section{References}

Barron MJ, McDonnell ST, MacKie I, and Dixon MJ. 2008. Hereditary dentine disorders: dentinogenesis imperfecta and dentine dysplasia. Orphanet Journal of Rare Diseases 3:1.

Chahine C, Cheung MS, Head TW, Schwartz S, Glorieux FH, and Rauch F. 2008. Tooth extraction socket healing in pediatric patients treated with intravenous pamidronate. Journal of Pediatrics 153:719-720.

Chang PC, Lin SY, and Hsu KH. 2007a. The craniofacial characteristics of osteogenesis imperfecta patients. European Journal of Orthodontics 29:232-237. 10.1093/ejo/cjl035

Chang PC, Lin SY, and Hsu KH. 2007b. The craniofacial characteristics of osteogenesis imperfecta patients. European Journal of Orthodontics 29:232-237.

Cheung MS, Arponen H, Roughley P, Azouz ME, Glorieux FH, Waltimo-Siren J, and Rauch F. 2011. Cranial base abnormalities in osteogenesis imperfecta: phenotypic and genotypic determinants. Journal of Bone and Mineral Research 26:405-413.

Cheung MS, and Glorieux FH. 2008. Osteogenesis Imperfecta: update on presentation and management. Reviews in Endocrine and Metabolic Disorders 9:153-160. 10.1007/s11154-008-9074-4

Delgado AC, Ruiz M, Alarcon JA, and Gonzalez E. 2008. Dentinogenesis imperfecta: the importance of early treatment. Quintessence International 39:257-263.

Eimar H, Tamimi F, Retrouvey JM, Rauch F, Aubin JE, and McKee MD. 2016. Craniofacial and Dental Defects in the Col1a1Jrt/+ Mouse Model of Osteogenesis Imperfecta. Journal of Dental Research 95:761-768. http://dx.doi.org/10.1177/0022034516637045

Fleisch H. 1991. Bisphosphonates. Drugs 42:919-944.

Fleisch HA. 1997. Bisphosphonates: preclinical aspects and use in osteoporosis. Annals of Medicine 29:55-62. 
340

Forlino A, and Marini JC. 2016. Osteogenesis imperfecta. Lancet 387:1657-1671. 10.1016/S01406736(15)00728-X

Glorieux FH. 2008. Osteogenesis imperfecta. Best Practice \& Research: Clinical Rheumatology 22:85-100. 10.1016/j.berh.2007.12.012

Hartsfield JK, Hohlt WF, and Roberts WE. 2006. Orthodontic treatment and orthognathic surgery for patients with osteogenesis imperfecta. Seminars in Orthodontics: Elsevier. p 254-271.

Hennedige AA, Jayasinghe J, Khajeh J, and Macfarlane TV. 2013. Systematic review on the incidence of bisphosphonate related osteonecrosis of the jaw in children diagnosed with osteogenesis imperfecta. Journal of Oral \& Maxillofacial Research 4:e1. http://dx.doi.org/10.5037/jomr.2013.4401

Herold RC. 1972. Fine structure of tooth dentine in human dentinogenesis imperfecta. Archives of Oral Biology 17:1009-1013.

Hoyer-Kuhn H, Semler O, and Schoenau E. 2014. Effect of denosumab on the growing skeleton in osteogenesis imperfecta. Journal of Clinical Endocrinoly \& Metabolism 99:3954-3955. 10.1210/jc.2014-3072

Jindal M, Maheshwari S, Verma R, and Khan MT. 2009. Comparative study of dentinogenesis imperfecta in different families of the same topographical region. Int J Clin Pediatr Dent 2:27-34. 10.5005/jp-journals-10005-1015

Johnson A, and Hodgson TA. 2010. Dental extractions in children with osteogenesis imperfecta managed with bisphosphonates. Oral Diseases 16 (6):571. http://dx.doi.org/10.1111/j.16010825.2010.01743.x

Kamoun-Goldrat A, Ginisty D, and Le Merrer M. 2008. Effects of bisphosphonates on tooth eruption in children with osteogenesis imperfecta. European Journal of Oral Sciences 116:195-198. 10.1111/j.1600-0722.2008.00529.x

Kapust AJ, Sinclair PM, and Turley PK. 1998. Cephalometric effects of face mask/expansion therapy in Class III children: a comparison of three age groups. American Journal of Orthodontics and Dentofacial Orthopedics 113:204-212.

Kim J-H, Viana MA, Graber TM, Omerza FF, and BeGole EA. 1999. The effectiveness of protraction face mask therapy: a meta-analysis. American Journal of Orthodontics and Dentofacial Orthopedics 115:675-685.

Kos M, Kuebler JF, Luczak K, and Engelke W. 2010. Bisphosphonate-related osteonecrosis of the jaws: a review of 34 cases and evaluation of risk. Journal of Cranio-Maxillofacial Surgery 38:255-259.

Leal C, Martins L, Verli F, de Souza M, and Ramos-Jorge M. 2010. Clinical, histological and ultrastructural characterization of type II dentinogenesis imperfecta. European Archives of Paediatric Dentistry 11:306-309.

Levin LS, Leaf SH, Jelmini RJ, Rose JJ, and Rosenbaum KN. 1983. Dentinogenesis imperfecta in the Brandywine isolate (DI type III): clinical, radiologic, and scanning electron microscopic studies of the dentition. Oral Surgery, Oral Medicine, Oral Pathology 56:267-274.

Lewis MK, and Stoker NG. 1987. Surgical management of the patient with osteogenesis imperfecta. Journal of Oral and Maxillofacial Surgery 45:430-437.

Lund AM, Jensen BL, Nielsen LA, and Skovby F. 1997. Dental manifestations of osteogenesis imperfecta and abnormalities of collagen I metabolism. Journal of Craniofacial Genetics and Developmental Biology 18:30-37.

Maines E, Monti E, Doro F, Morandi G, Cavarzere P, and Antoniazzi F. 2012. Children and adolescents treated with neridronate for osteogenesis imperfecta show no evidence of any osteonecrosis of the jaw. Journal of Bone and Mineral Metabolism 30:434-438.

Majorana A, Bardellini E, Brunelli PC, Lacaita M, Cazzolla AP, and Favia G. 2010. Dentinogenesis imperfecta in children with osteogenesis imperfecta: a clinical and ultrastructural study. 
401

402

403

404

405

406

407

408

409

410

411

412

413

414

415

416

417

418

419

420

421

422

423

424

425

426

427

428

429

430

431

432

433

434

International Journal of Paediatric Dentistry 20:112-118. http://dx.doi.org/10.1111/j.1365263X.2010.01033.x

Malmgren B, Andersson K, Lindahl K, Kindmark A, Grigelioniene G, Zachariadis V, Dahllof G, and Astrom E. 2016. Tooth agenesis in osteogenesis imperfecta related to mutations in the collagen type I genes. Oral Diseases.

Malmgren B, and Lindskog S. 2003. Assessment of dysplastic dentin in osteogenesis imperfecta and dentinogenesis imperfecta. Acta Odontologica Scandinavica 61:72-80.

Malmgren B, and Norgren S. 2002a. Dental aberrations in children and adolescents with osteogenesis imperfecta. Acta Odontologica Scandinavica 60:65-71.

Malmgren B, and Norgren S. 2002b. Dental aberrations in children and adolescents with osteogenesis imperfecta. Acta Odontologica Scandinavica 60:65-71.

Mandall N, Cousley R, DiBiase A, Dyer F, Littlewood S, Mattick R, Nute SJ, Doherty B, Stivaros N, McDowall R, Shargill I, and Worthington HV. 2016. Early class III protraction facemask treatment reduces the need for orthognathic surgery: a multi-centre, two-arm parallel randomized, controlled trial. Journal of Orthodontics 43:164-175.

O'Connell AC, and Marini JC. 1999. Evaluation of oral problems in an osteogenesis imperfecta population. Oral Surgery Oral Medicine Oral Pathology Oral Radiology \& Endodontics 87:189196.

O'Connell A, and Marini J. 1999. Evaluation of oral problems in an osteogenesis imperfecta population. Oral Surgery, Oral Medicine, Oral Pathology, Oral Radiology, and Endodontology 87:189-196.

Orwoll ES, Shapiro J, Veith S, Wang Y, Lapidus J, Vanek C, Reeder JL, Keaveny TM, Lee DC, Mullins MA, Nagamani SC, and Lee B. 2014. Evaluation of teriparatide treatment in adults with osteogenesis imperfecta. Journal of Clinical Investigations 124:491-498. 10.1172/JCI71101

Paterson C, MCALLION S, and Miller R. 1983. Heterogeneity of osteogenesis imperfecta type I. Journal of Medical Genetics 20:203-205.

Prabhu N, Duckmanton N, Stevenson AR, and Cameron A. 2007. The placement of osseointegrated dental implants in a patient with type IV B osteogenesis imperfecta: a 9-year follow-up. Oral Surgery, Oral Medicine, Oral Pathology, Oral Radiology and Endodontics 103:349-354.

Prockop DJ. 2017. The exciting prospects of new therapies with mesenchymal stromal cells. Cytotherapy 19:1-8. 10.1016/j.jcyt.2016.09.008

Rauch F, Cornibert S, Cheung M, and Glorieux FH. 2007. Long-bone changes after pamidronate discontinuation in children and adolescents with osteogenesis imperfecta. Bone 40:821-827. 10.1016/j.bone.2006.11.020

Rauch F, and Glorieux FH. 2004. Osteogenesis imperfecta. Lancet 363:1377-1385.

Rauch F, Travers R, Plotkin H, and Glorieux FH. 2002. The effects of intravenous pamidronate on the bone tissue of children and adolescents with osteogenesis imperfecta. The Journal of clinical investigation 110:1293-1299.

Rizkallah J, Schwartz S, Rauch F, Glorieux F, Vu DD, Muller K, and Retrouvey JM. 2013. Evaluation of the severity of malocclusions in children affected by osteogenesis imperfecta with the peer assessment rating and discrepancy indexes. American Journal of Orthodontics and Dentofacial Orthopedics 143:336-341. http://dx.doi.org/10.1016/j.ajodo.2012.10.016

Ruck J, Dahan-Oliel N, Montpetit K, Rauch F, and Fassier F. 2011. Fassier-Duval femoral rodding in children with osteogenesis imperfecta receiving bisphosphonates: functional outcomes at one year. Journal of Children's Orthopaedics 5:217-224.

Ruggiero SL, Mehrotra B, Rosenberg TJ, and Engroff SL. 2004. Osteonecrosis of the jaws associated with the use of bisphosphonates: a review of 63 cases. Journal of Oral and Maxillofacial Surgery 62:527-534. 
435

436

437

438

439

440

441

442

443

444

445

446

447

448

449

450

451

452

453

454

455

456

457

458

459

460

461

462

463

464

465

466

467

468

469

470

471

472

473

474

475

476

477

478

479
Sæves R, Wekre LL, Ambjørnsen E, Axelsson S, Nordgarden H, and Storhaug K. 2009. Oral findings in adults with osteogenesis imperfecta. Special Care in Dentistry 29:102-108.

Schwartz S, Joseph C, lera D, and Vu D-D. 2008. Bisphosphonates, osteonecrosis, osteogenesis imperfecta and dental extractions: A case series. Journal of the Canadian Dental Association 74:537-542.

Schwartz S, and Tsipouras P. 1984a. Oral findings in osteogenesis imperfecta. Oral surgery, oral medicine, and oral pathology 57:161-167.

Schwartz S, and Tsipouras P. 1984b. Oral findings in osteogenesis imperfecta. Oral Surg Oral Med Oral Pathol 57:161-167.

Shapira S. 2001. Dentinogenesis imperfecta: an early treatment strategy. Pediatric Dentistry 23.

Shapiro JR, Kantipuly A, and Rowe D. 2010. Osteogenesis imperfecta: Current and future treatments. Drugs of the Future 35:575-584. http://dx.doi.org/10.1358/dof.2010.035.07.1485772

Shields ED. 1983. A new classification of heritable human enamel defects and a discussion of dentin defects. Birth Defects Original Article Series 19:107-127.

Shields ED, Bixler D, and El-Kafrawy AM. 1973. A proposed classification for heritable human dentine defects with a description of a new entity. Archives of Oral Biology 18:543-IN547. http://dx.doi.org/10.1016/0003-9969(73)90075-7

Siadat $\mathrm{H}$, Alikhasi $\mathrm{M}$, and Mirfazaelian A. 2007. Rehabilitation of a patient with amelogenesis imperfecta using all-ceramic crowns: a clinical report. The Journal of prosthetic dentistry 98:85-88.

Sillence DO, Senn A, and Danks DM. 1979. Genetic heterogeneity in osteogenesis imperfecta. Journal of Medical Genetics 16:101-116.

Tashima H, Wattanawong K, Ho C-T, Wen-Ching-Ko E, Nguyen A, and Lo L-J. 2011. Orthognathic surgery considerations for patients with undiagnosed type I osteogenesis imperfecta. Journal of Oral and Maxillofacial Surgery 69:2233-2241.

Teixeira CS, Santos Felippe MC, Felippe WT, Correa Silva-Sousa YT, and Sousa-Neto MD. 2008. The role of dentists in-diagnosing osteogenesis imperfecta in patients with dentinogenesis imperfecta. Journal of the American Dental Association 139:906-914.

Vital SO, Gaucher C, Bardet C, Rowe P, George A, Linglart A, and Chaussain C. 2012. Tooth dentin defects reflect genetic disorders affecting bone mineralization. Bone 50:989-997.

Waltimo-Siren J, Kolkka M, Pynnonen S, Kuurila K, Kaitila I, and Kovero O. 2005. Craniofacial features in osteogenesis imperfecta: a cephalometric study. American Journal of Medical Genetics Part $A$ 133A:142-150. 10.1002/ajmg.a.30523

Waltimo J, Ojanotko-Harri A, and Lukinmaa PL. 1996a. Mild forms of dentinogenesis imperfecta in association with osteogenesis imperfecta as characterized by light and transmission electron microscopy. Journal of Oral Pathology and Medicine 25:256-264.

Waltimo J, Ojanotko-Harri A, and Lukinmaa PL. 1996b. Mild forms of dentinogenesis imperfecta in association with osteogenesis imperfecta as characterized by light and transmission electron microscopy. Journal of Oral Pathology and Medicine 25:256-264.

Wannfors K, Johansson C, and Donath K. 2009. Augmentation of the mandible via a "tent-pole" procedure and implant treatment in a patient with type III osteogenesis imperfecta: clinical and histologic considerations. International Journal of Oral and Maxillofacial Implants 24:1144-1148.

Wright JT, and Gantt DG. 1985. The ultrastructure of the dental tissues in dentinogenesis imperfecta in man. Archives of Oral Biology 30:201-206. 
Figure 1

Subject affected by OI type IV with DI.

This picture was selected from the authors' archives.

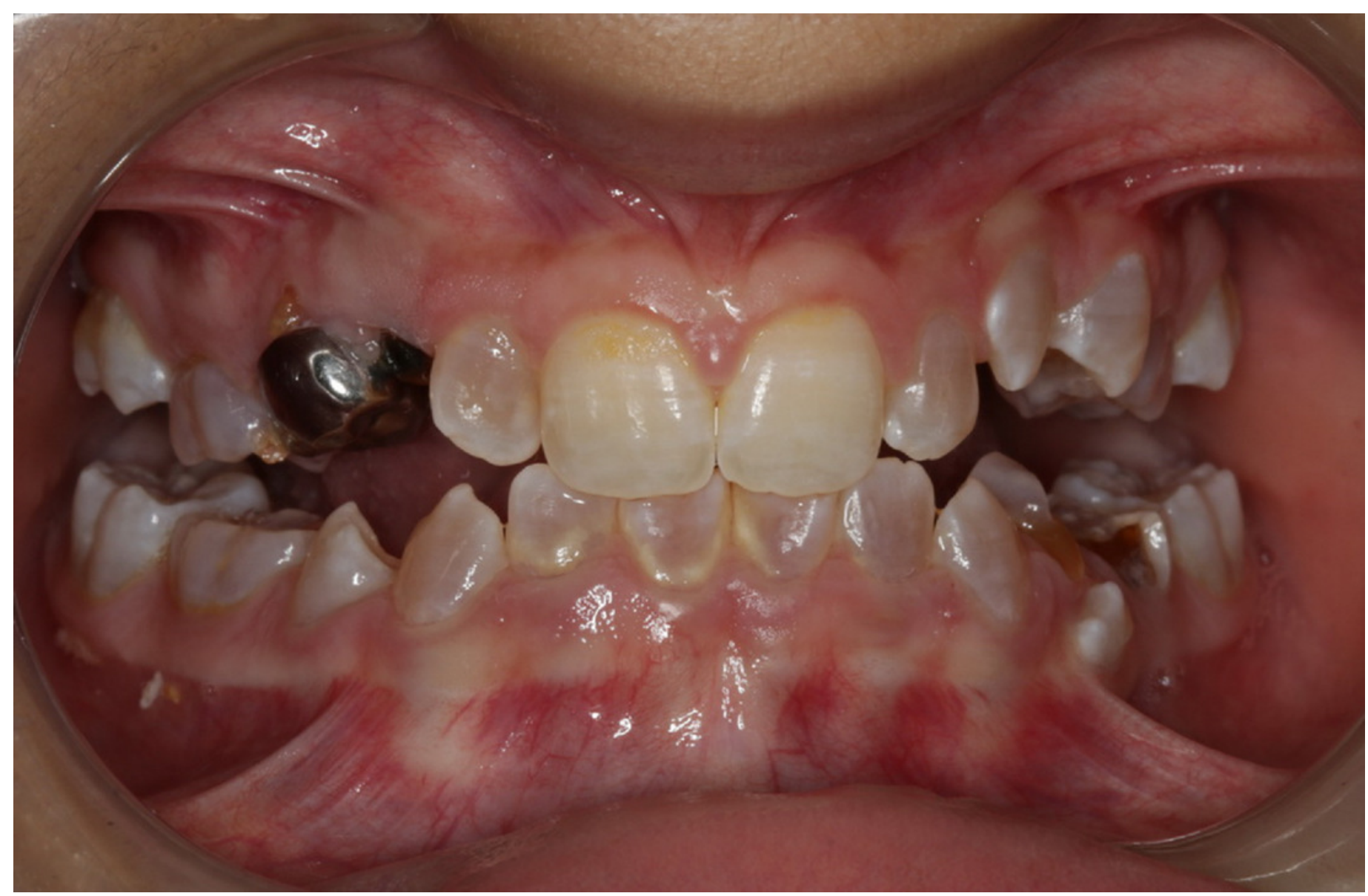




\section{Figure 2}

Panoramic radiograph of a subject affected by OI type III with missing teeth and DI.

This picture was selected from the authors' archives.

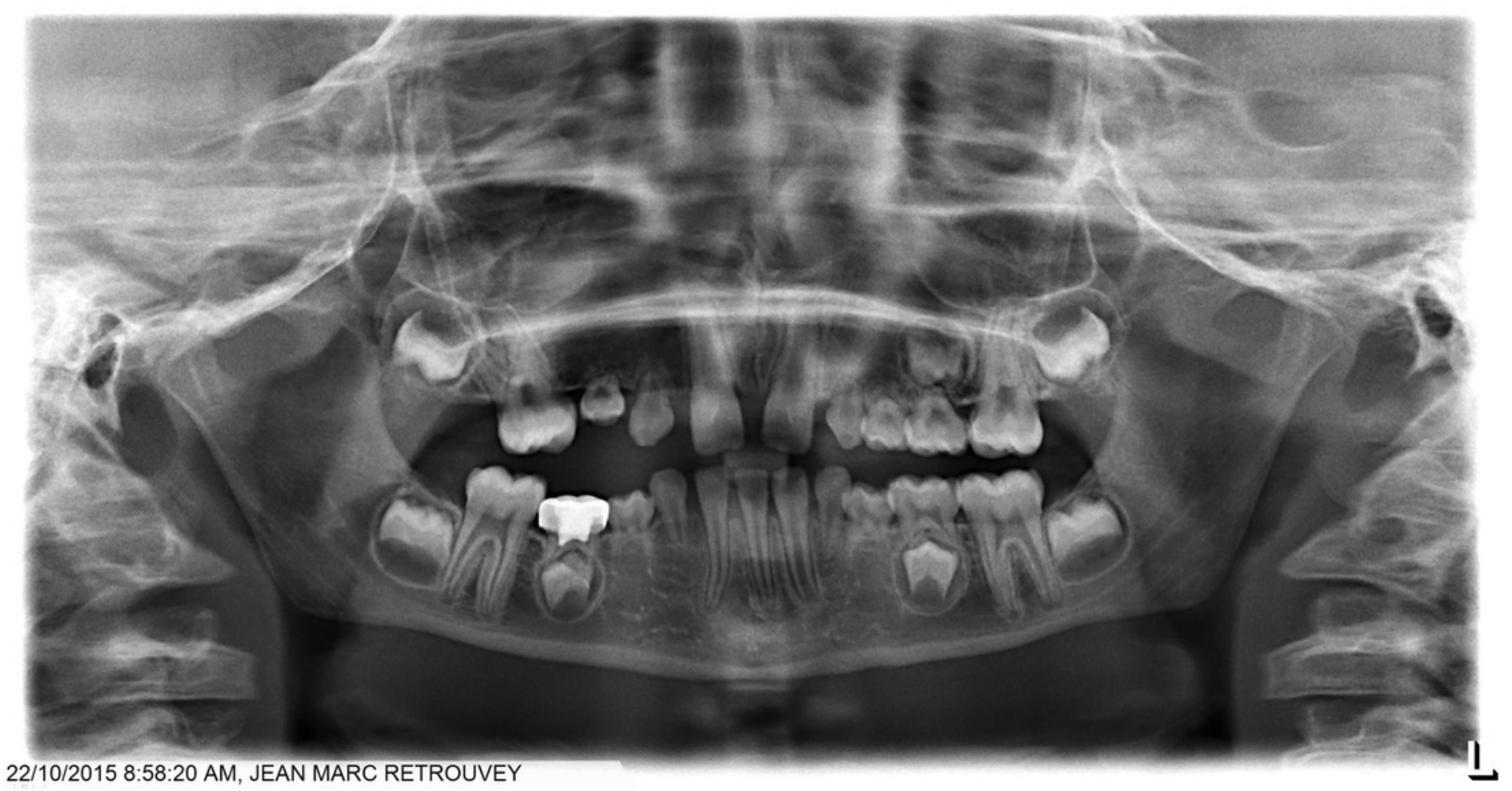


Figure 3

Young subject affected by OI type III with a severe class III malocclusion.

This picture was selected from the authors' archives. 


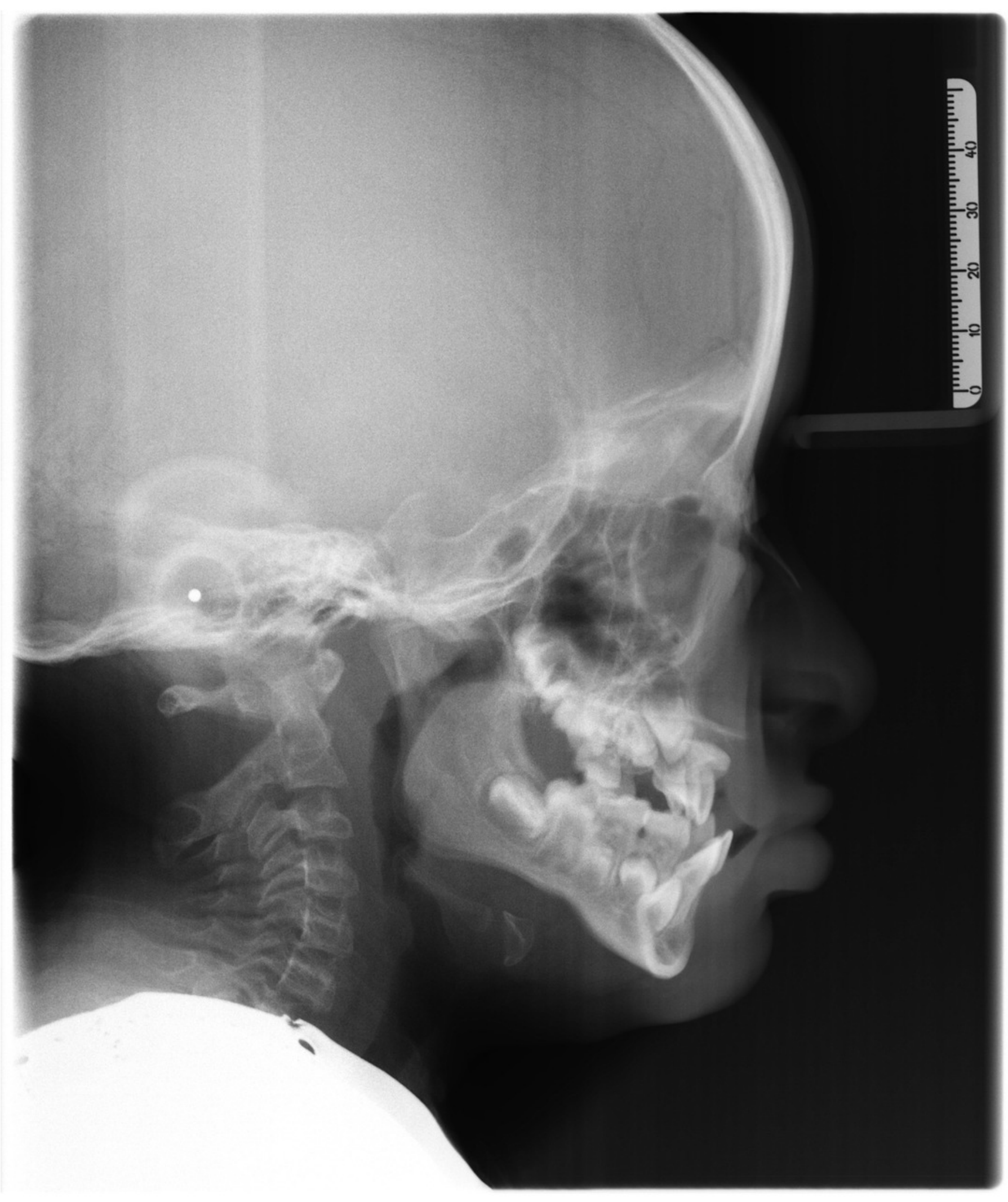


Figure 4

Lateral openbite on a subject affected by OI type IV treated with the Invisalign appliance.

This picture was selected from the authors' archives. 


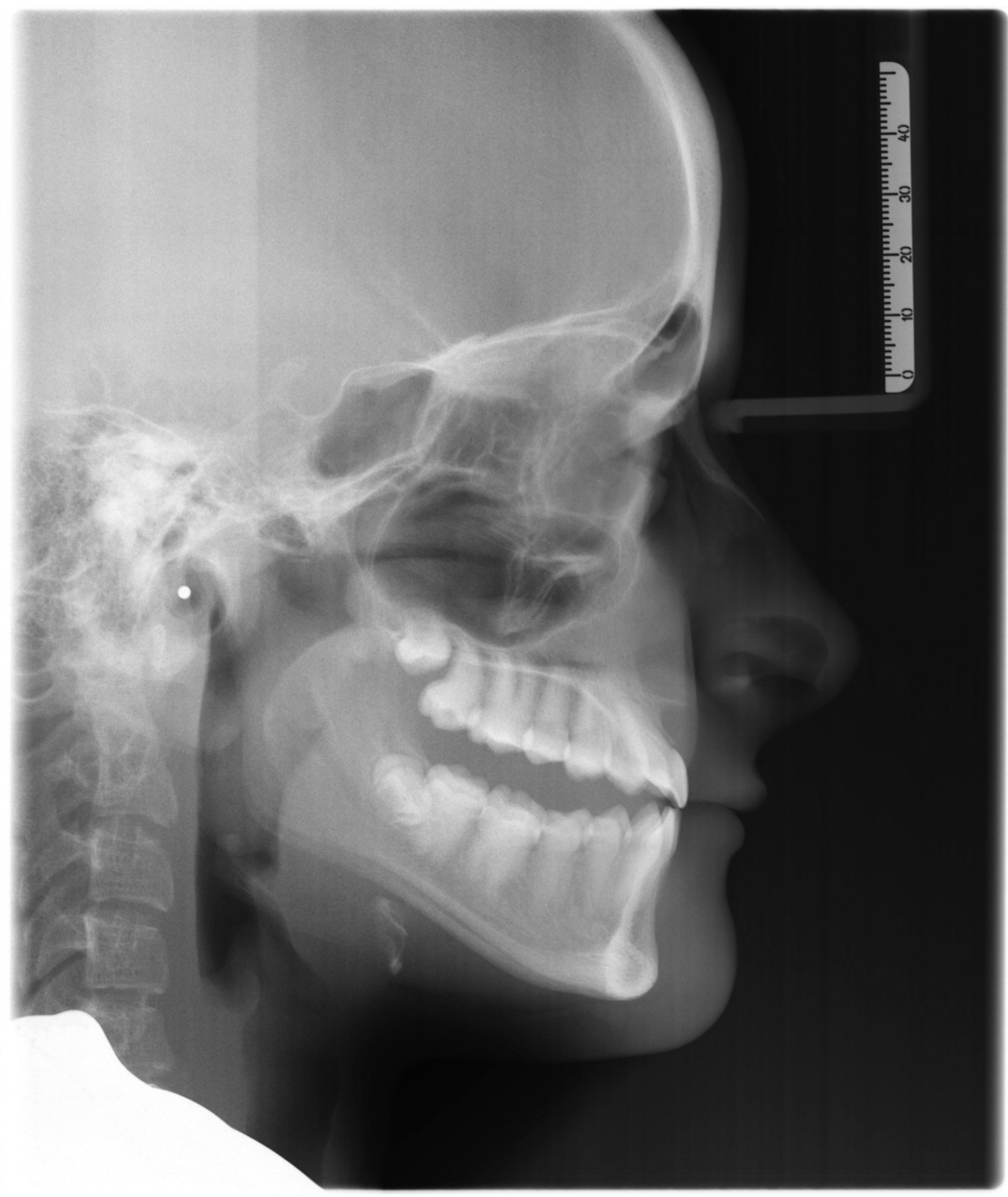




\section{Figure 5}

CBCT volume rendering of subjects affected by OI to different degrees of severity

(A, B, C, D) OI type I subject presenting with end to end anterior relation, full cusp class III malocclusion and without sever skeletal deformities. (E, F, G, H) Ol type type IV subject presenting with missing teeth, class III malocclusion with negative overjet, asymmetry and slight skeletal deformities. (I, J, K, L) OI type III subject presenting with severe class III malocclusion, anterior openbite and pronounced skeletal abnormalities. This picture was selected from the authors' archives.

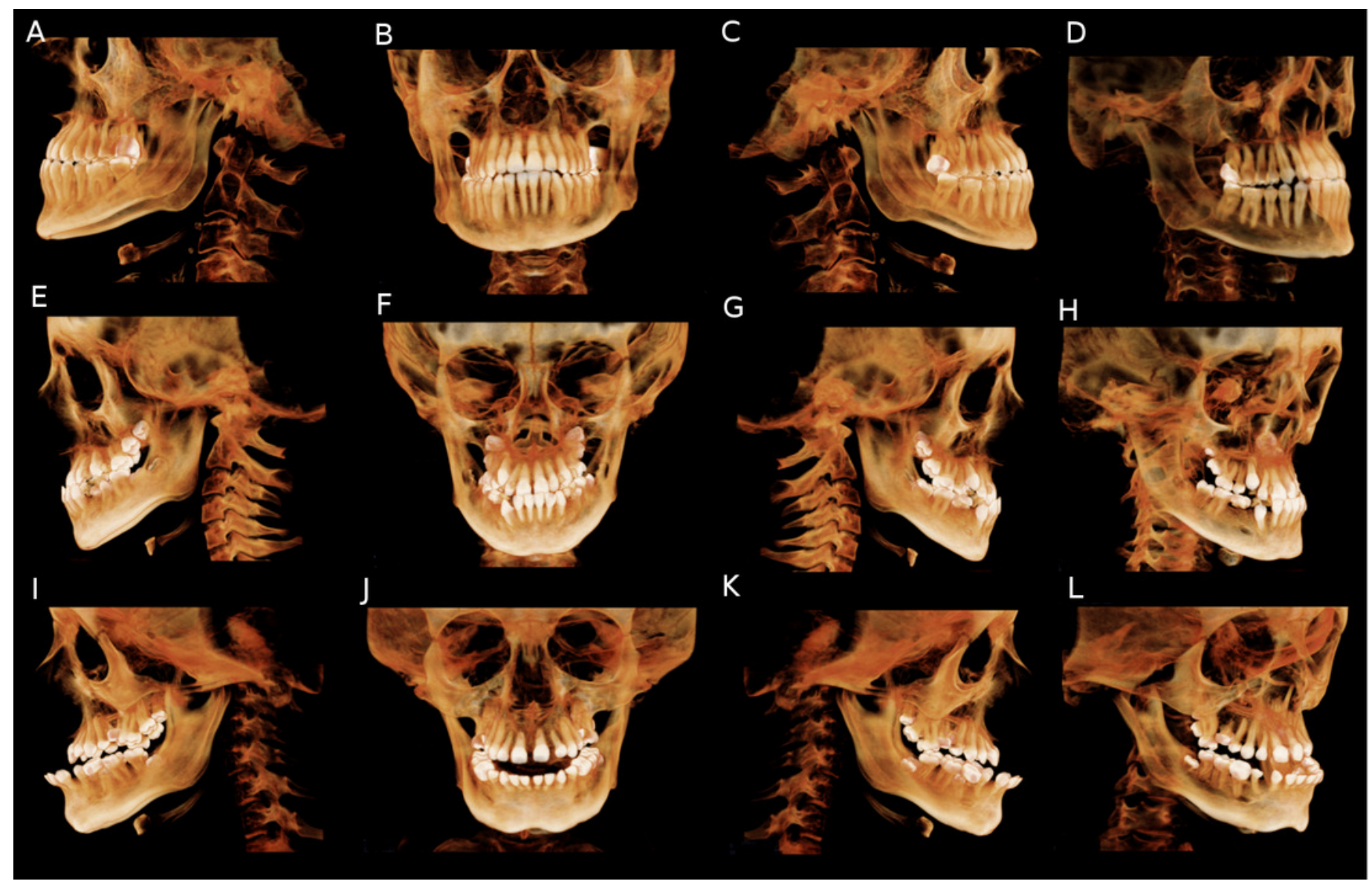


Table $\mathbf{1}$ (on next page)

Characteristics of subjects affected by Ol according to types. 
1 Table 1: Characteristics of OI by types

\begin{tabular}{|c|c|}
\hline & Characteristics \\
\hline $\begin{array}{l}\text { Type I: Mild non-deforming } \\
\text { Osteogenesis Imperfecta }\end{array}$ & $\begin{array}{l}\text { Normal height, or mild short stature; blue sclera; low rate of } \\
\text { dentinogenesis imperfecta }(20 \%)\end{array}$ \\
\hline Type II: Perinatal lethal & $\begin{array}{l}\text { Multiple rib and long bone fractures at birth; pronounced } \\
\text { deformities; broad long bones; low density of skull bones on } \\
\text { radiograph, dark sclera }\end{array}$ \\
\hline Type III: Severely deforming & $\begin{array}{l}\text { Very short; triangular face; low ears, severe scoliosis; greyish sclera; } \\
\text { dentinogenesis imperfecta }(80 \%)\end{array}$ \\
\hline $\begin{array}{l}\text { Type IV: Moderately } \\
\text { deforming }\end{array}$ & $\begin{array}{l}\text { Moderately short; mild to moderate scoliosis; greyish or white } \\
\text { sclera; dentinogenesis imperfecta }(60 \%)\end{array}$ \\
\hline $\begin{array}{l}\text { Type V: Moderately } \\
\text { deforming }\end{array}$ & $\begin{array}{l}\text { Similar fracture incidence and long-bone deformities to type IV; } \\
\text { Hyperplastic callus formation; calcification of the interosseous } \\
\text { forearm membrane }\end{array}$ \\
\hline $\begin{array}{l}\text { Type VI: Moderately to } \\
\text { severely deforming }\end{array}$ & $\begin{array}{l}\text { Moderately short; scoliosis; accumulation of osteoid in bone tissue, } \\
\text { fish scale pattern of bone lamellation; white sclera; no } \\
\text { dentinogenesis imperfecta }\end{array}$ \\
\hline $\begin{array}{l}\text { Type VII: Moderately } \\
\text { deforming }\end{array}$ & $\begin{array}{l}\text { Mild short stature; short humeri and femora; white sclera; no } \\
\text { dentinogenesis imperfecta }\end{array}$ \\
\hline
\end{tabular}

